\title{
The characteristics of recycling gas drilling technology
}

\author{
Yang Shunji ${ }^{1 *}$, Liu Gonghui ${ }^{1,2}$ and Li Jun ${ }^{1}$ \\ ${ }^{1}$ Key Laboratory of Petroleum Engineering of the Ministry of Education, China University of Petroleum, Beijing 102249, China \\ ${ }^{2}$ Beijing Union University, Beijing 100011, China
}

(C) China University of Petroleum (Beijing) and Springer-Verlag Berlin Heidelberg 2012

\begin{abstract}
Recycling gas drilling is a new drilling technology. This paper can be divided into three parts, with the purpose of introducing and analyzing the characteristics of this new technology. First, the major equipment characteristic of this technology was introduced. Secondly, compared with conventional gas drilling, Angel's model was used to analyze the wellbore flow characteristics. Due to the closed loop and the effect of back pressure caused by the equipment, the gas flow rate decreases dramatically during drilling. Apart from this, it is also found that the kinetic energy at the casing shoe is always smaller than that at the top of the collar. The proposing of the drilling limit concept points out the basic difference between the two gas drilling technologies. Lastly, according to the results of the theoretical analysis, gas supplement operations for the wellbore must be conducted. Thus, two gas supplement schemes are presented in this paper, to provide some guidance for field operations.
\end{abstract}

Key words: Recycling gas drilling technology, major equipment, flow characteristics, comparative analysis, gas supplement scheme

\section{Introduction}

Drilling oil and gas wells with air, natural gas, carbon dioxide, and nitrogen has become a mature technology since the 1950s (Angel, 1957). This technology, called underbalanced drilling (UBD), has traditionally been used for increasing rate of penetration in hard formations (Lyons et al, 2001; Nas et al, 2010). It is also utilized for solving the problem of loss of circulation in depleted reservoirs and naturally fractured reservoirs such as those reported by Allan (1994) and Hou et al (2005). These advantages have made significant differences in several field cases (Chen et al, 2006). Recently, this technology has been employed to drill hydrocarbon-bearing formations to reduce fluid damage (Lyons et al, 2008). These formations include lowpermeability gas reservoirs and coal bed methane pay zone (Cox et al, 1999). Meanwhile, there are also some problems which are not handled perfectly (Malloy et al, 2007; Zhu et al, 2010; Zhao et al, 2010).

Compared with dry air and natural gas, nitrogen gas is preferred in drilling as it is inert and non-inflammability (Cowar and Jones, 1952; Zabetakis, 1964; Allan, 1994). However, the biggest shortcoming of employing nitrogen gas as the drilling fluid is the high cost of manufacturing. In most cases, the return gas is still predominantly nitrogen unless the well is a prolific gas producer. Therefore, if the nitrogen

*Corresponding author. email: yangshunji123@163.com

Received June 20, 2011 gas returned from the wellbore can be recycled by ground equipment and injected back into the wellbore again, nitrogen gas drilling will have a better prospect (Lunan, 1994; Teichrob, 1994). The concept of recycling gas drilling is proposed in this paper to achieve this idea. In previous research and field tests, we have acquired some mature results of recycling gas drilling technology (Wu et al, 2009; Liu et al, 2009; Li et al, 2010a; 2010b; Tao et al, 2010). However, the drilling design and operation scheme of drilling with return gas are quite different from conventional gas drilling. Therefore, in this paper, Angel's model is used to analyze characteristics of wellbore flow of recycling gas drilling. Based on the analytical results, two gas supplement schemes are proposed which play a positive role in guiding the field operation.

\section{Introduction to recycling gas drilling technology}

Recycling gas drilling technology is proposed and developed on the basis of the conventional gas drilling. The main characteristics of this technology is that the gas returned from the wellbore is purified by a separation and filtration system, and then injected back into the wellbore instead of being discharged directly.

Fig. 1 illustrates a sketch of the recycling gas drilling system at surface. The work gas from the gas supplier can be nitrogen gas from a small $\mathrm{N}_{2}$ generator, natural gas, or tail gas. The work gas fed to the compressors and booster is injected into the well through the standpipe. Drilling 
operation starts as soon as the gas volume and pressure in the well is high enough. The gas stream returned to the surface goes through three stages of separation (Fig. 2) to remove solids and liquids. The purified gas is led to the suction end of the compressors and recycling. Because the return gas is reused, only a small amount of make-up gas is needed from the gas supplier for the requirement of the wellbore extension and possible gas leakage. The recycling gas drilling can significantly reduce the cost of drilling by using less work gas from a small gas supplier.

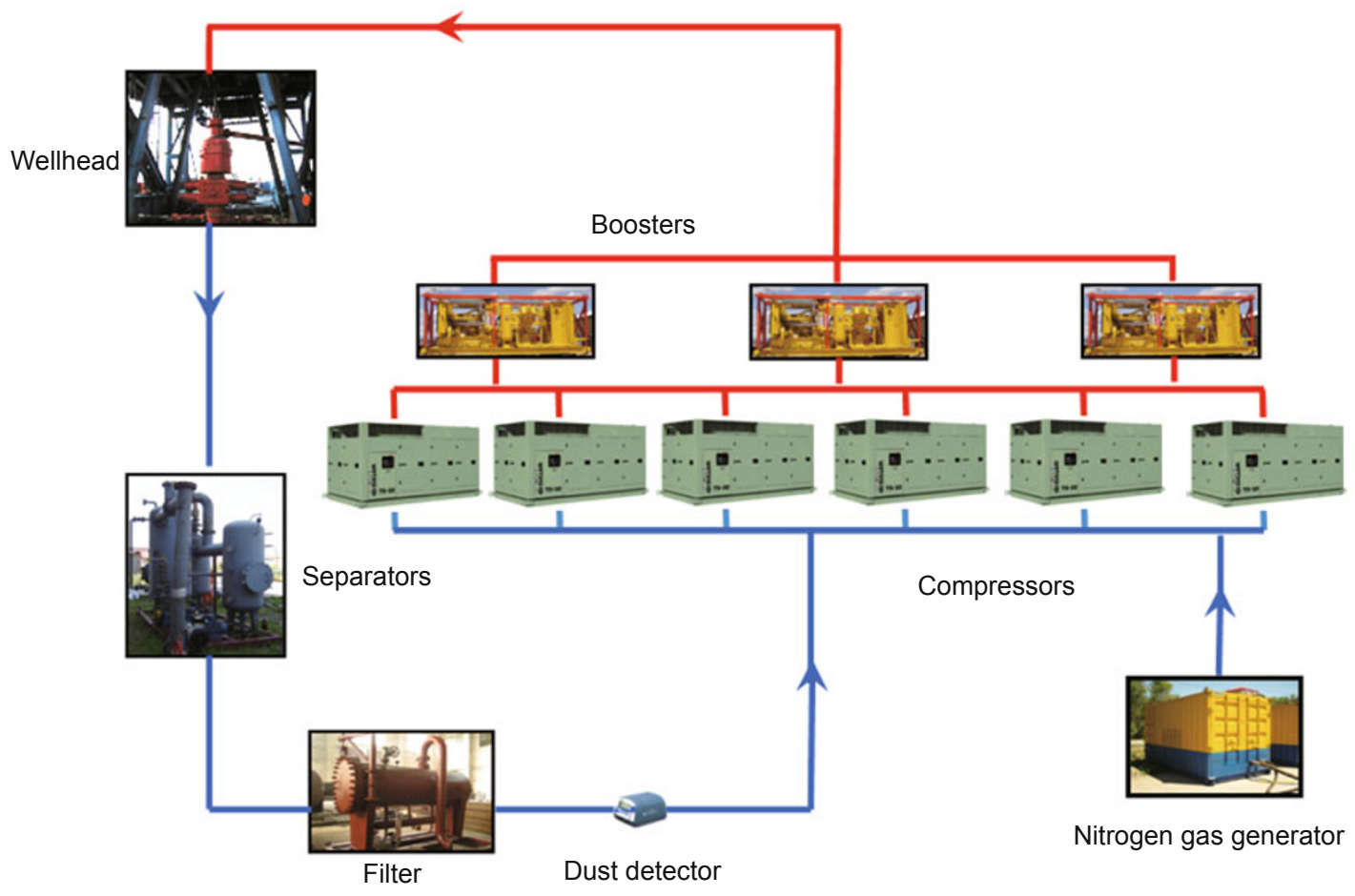

Fig. 1 Sketch of the recycling gas drilling system

The components of the recycling gas drilling system are further described as follows:

1) Gas supplier. The gas supplier can be a small nitrogen generator, natural gas pipeline, or $\mathrm{CO}_{2}$ pipeline. In most applications, a small-size nitrogen generator with on-site membrane separation is feasible and cost-effective.

2) Compressors and boosters. These are standard equipment currently used in gas drilling operations. The suction end of the compressors can be modified to adapt to the recycling gas drilling system.

3) Inertial separator. This is the first stage separation that removes a great quantity of large drilling cuttings of greater than $0.1 \mathrm{~mm}$ and liquids by means of inertial force. The output nitrogen stream is fed to next separator for further separation.

4) Cyclone separator. This is a second-stage separator that removes cuttings of greater than $7 \mu \mathrm{m}$ and liquid using centrifugal force. The outlet nitrogen gas is fed next separator for purification.

5) Precision filter. This is the last stage separation, comprised of a fiberglass filter element that removes all particles greater than $1 \mu \mathrm{m}$ by filtration and aggregation.

6) Discharge system. This is a specially designed system that discharges cuttings and liquids with minimal loss of work gas.

The fiberglass filter elements will eventually be blocked

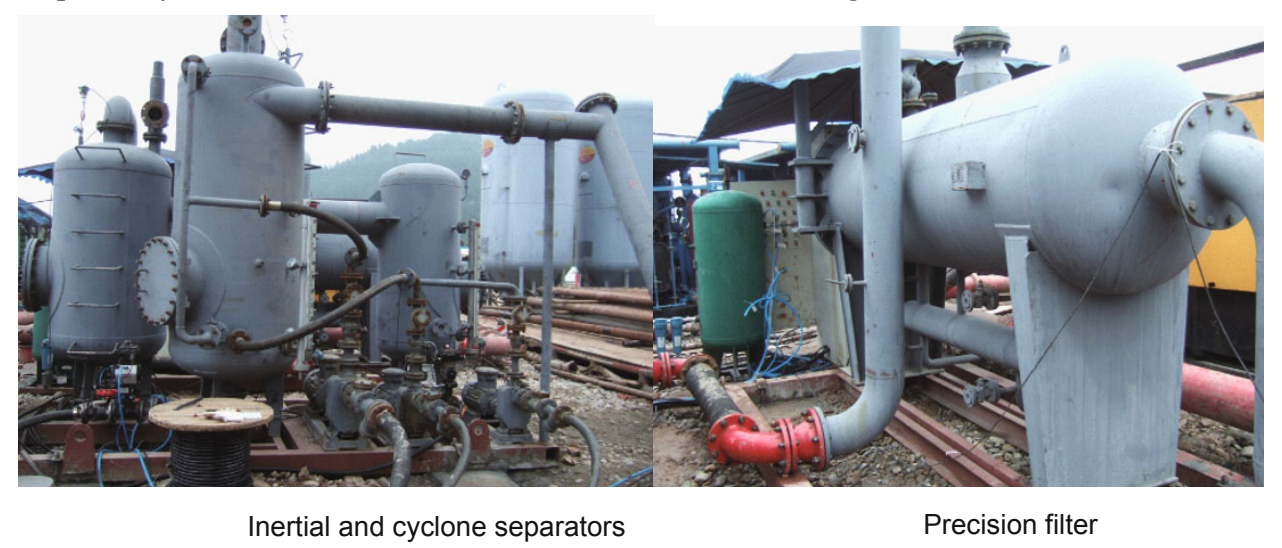

Fig. 2 Three stages of separation 
by small cuttings, which will generate a small back pressure at the surface (Fu et al, 2009). The back pressure includes the pressure drops of the blooie line, cyclone separators, fine filter and the inlet of compressors, which makes the calculation very complex:

$$
p_{\mathrm{b}}=p_{1}+p_{\mathrm{c}}+p_{\mathrm{f}}+p_{\text {ip }}
$$

where $p_{\mathrm{b}}$ is the back pressure, $\mathrm{MPa} ; p_{\mathrm{l}}, p_{\mathrm{c}}, p_{\mathrm{f}}$ and $p_{\text {ip }}$ are the pressure drops of the blooie line, cyclone separators, fine filter and the compressor inlet, respectively, MPa.

However, according to the current technological design and field tests, the maximum back pressure should not exceed $0.05 \mathrm{MPa}(\mathrm{Fu}$ et al, 2008; 2009). In this paper the back pressure gradient is set at $0.01 \mathrm{MPa} / 100 \mathrm{~m}$.

\section{Wellbore flow models for drilling with return gas}

During gas drilling, the flow of compressible gas of a fixed mass within a closed loop system is pipe flow and described by the laws of mass conservation and momentum conservation. The relationship between the flow rate, pressure and temperature follows the equation of state of an ideal gas.

The upward vertical flow in the annulus can be described in the discrete form (Guo et al, 1994; Gas Research Institute, 1997):

$$
\begin{aligned}
& \Delta p_{i}^{\text {annulus }}=\left(\frac{f_{\text {annulus }} v_{\text {mix }}^{2} \rho_{i}^{\text {mix }}}{2 \cdot\left(D_{\mathrm{h}}-D_{\mathrm{p}}\right)}+g\right) \cdot\left(h_{i+1}-h_{i}\right) \\
& p_{i=0}^{\text {annulus }}=p_{\mathrm{b}} \quad p_{i+1}^{\text {annulus }}=\Delta p_{i}^{\text {annulus }}+p_{i}^{\text {annulus }}
\end{aligned}
$$

The downward vertical flow in the drill pipe can be expressed in the discrete form (Guo et al, 1994; Gas Research Institute, 1997):

$$
\begin{aligned}
& \Delta p_{i}^{\text {pipe }}=\left(\frac{f_{\text {pipe }} v_{\text {gas }}^{2} \rho_{i}^{\text {gas }}}{2 \cdot d_{\mathrm{p}}}+g\right) \cdot\left(h_{i}-h_{i+1}\right) \\
& p_{i=h}^{\text {pipe }}=\Delta p_{\text {bit }}+p_{i=h}^{\text {annulus }} \quad p_{i-1}^{\text {pipe }}=\Delta p_{i}^{\text {pipe }}+p_{i}^{\text {pipe }}
\end{aligned}
$$

where $\Delta p_{i}^{\text {annulus }}$ is the pressure drop in infinitesimal segment $i$ in the annulus, $\mathrm{Pa} ; f_{\text {annulus }}$ is the Fanning friction factor in the annulus; $v_{\text {mix }}$ is the velocity of gas-solid mixtures in the annulus, $\mathrm{m} / \mathrm{s} ; \rho_{i}^{\text {mix }}$ is the average density of gas-solid mixtures in infinitesimal segment $i$ in the annulus, $\mathrm{kg} / \mathrm{m}^{3} ; p_{i}^{\text {annulus }}$ is the pressure at infinitesimal segment $i, \mathrm{~Pa} ; \Delta p_{i}^{\text {pipe }}$ is the pressure drop in infinitesimal segment $i$ in the drill pipe, $\mathrm{Pa} ; f_{\text {pipe }}$ is the Fanning friction factor in the drill pipe, dimensionless; $v_{\text {gas }}$ is the velocity of gas in the drill pipe, $\mathrm{m} / \mathrm{s} ; \rho_{i}{ }^{\text {gas }}$ is the gas density in infinitesimal segment $i$ in the drill pipe, $\mathrm{kg} / \mathrm{m}^{3} ; p_{i}^{\text {pipe }}$ is the pressure in infinitesimal segment $i$ in the drill pipe, $\mathrm{Pa} ; h_{i}$ is the well depth of infinitesimal segment $i ; \Delta p_{\text {bit }}$ is the pressure drop in the drill bit, $\mathrm{Pa} ; D_{\mathrm{h}}$ is the well diameter, $\mathrm{m} ; D_{\mathrm{p}}$ is the outside diameter of the drill pipe, $\mathrm{m}$; $d_{\mathrm{p}}$ is the inside diameter of the drill pipe, $\mathrm{m} ; \mathrm{g}$ is the acceleration of gravity, $\mathrm{m} / \mathrm{s}^{2}$.

\section{The changes of flow parameters during gas drilling}

The drilling process at a depth of 2,500-3,000 m was simulated for both recycling gas and conventional gas drilling. Flow parameters in both gas drilling operations were analyzed, and the concept of the drilling limit and the selection criterion of critical points for recycling gas drilling were proposed. The calculated parameters are shown in Table 1. The initial gas injection rates in both gas drilling operations at the depth of $2,500 \mathrm{~m}$ are $100 \mathrm{Nm}^{3} / \mathrm{min}$.

Table 1 The parameters of S10D wellbore configuration

\begin{tabular}{ccccc}
\hline Well depth, $m$ & Upper casing length, $\mathrm{m}$ & Drill pipe ID, mm & Collar ID, mm & Collar length, m \\
\hline $2500-3000$ & 2300 & 97.1804 & 71.4375 & 150 \\
\hline Hole diameter, mm & Casing ID, mm & Drill pipe OD, mm & Collar OD, mm & Nozzle diameter, mm \\
\hline 215.9 & 244.475 & 114.3 & 168.275 & 17.78 \\
\hline
\end{tabular}

\subsection{The changes of gas flow rate and total gas mass in the wellbore during drilling}

The total mass of the gas in the wellbore is affected by many factors, mainly including the wellbore pressure profile, gas stream temperature, gas circulation rate, hole configuration and the drill string assembly. The calculation steps are as follows:

1) Calculate the temperature profiles in the annulus and the drill pipe;

2) Calculate the pressure profiles in the annulus and the drill pipe;

3) Calculate the density profiles in the annulus and the drill pipe;
4) Calculate the total gas mass in the wellbore.

The total mass of the gas in the wellbore is estimated as follows:

$$
M=\frac{\pi}{4} \int_{H}^{0} \rho_{\text {gas }}\left(D_{\mathrm{h}}-D_{\mathrm{p}}\right)^{2} \mathrm{~d} h+\frac{\pi}{4} \int_{0}^{H} \rho_{\text {gas }} d_{\mathrm{p}}^{2} \mathrm{~d} h
$$

where $M$ is the total mass of the gas in the wellbore, $\mathrm{kg} ; \rho_{\text {gas }}$ is the gas density in the wellbore, $\mathrm{kg} / \mathrm{m}^{3} ; H$ is the well depth, $\mathrm{m}$.

In conventional gas drilling, the total mass of the gas in the wellbore increases linearly with increasing depth (Fig. 3). However, due to the gas circulating in the closed loop system, the total mass of the gas in the wellbore maintains its original value in drilling with return gas. As a result, the gas flow rate 
decreases linearly with depth in recycling gas drilling (Fig. 4).

Fig. 4 also shows a comparison of the gas flow rate under back-pressure or not in recycling gas drilling. The gas flow rate changes more quickly when drilling at a specified back pressure than when drilling without building up back pressure. Moreover, with an increase in the back pressure, the gas flow rate changes significantly. This change can be explained by the flow parameter distribution along the wellbore. Figs. 5 and 6 show the impact of back pressure on the pressure and gas velocity profiles. Due to back pressure, the gas expansion and flow are inhibited, which further leads to an increase in the gas density in the wellbore. At the same time, the total mass of gas in the closed loop system is fixed, and then the gas velocity in the wellbore when drilling at back pressure is lower than that when no back pressure is applied on the drilling fluid based on the law of mass conservation. Moreover, as the gas flow rate reduces, the total decrease in the gas column pressure and the friction loss is higher than the back pressure, which means the standpipe pressure when drilling at back pressure is lower than that when no back pressure is applied on the drilling fluid.

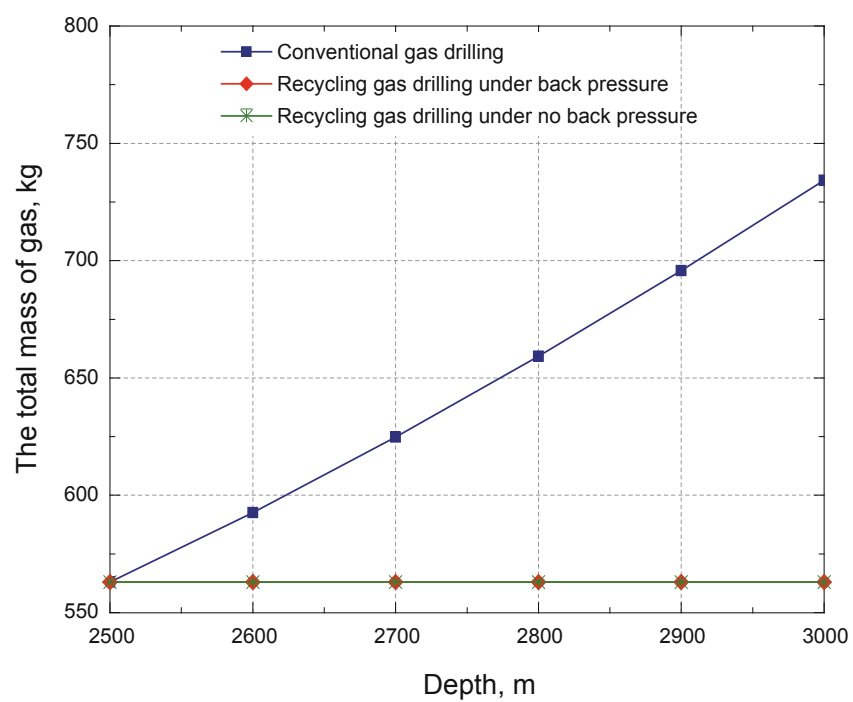

Fig. 3 The total mass of gas in the wellbore changing with well depth

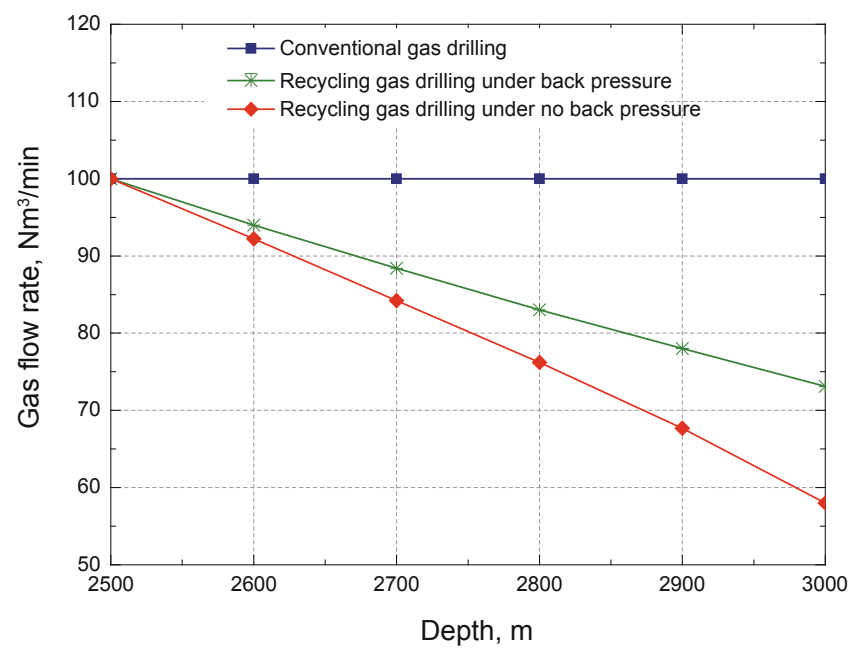

Fig. 4 The flow rate in the wellbore changing with well depth

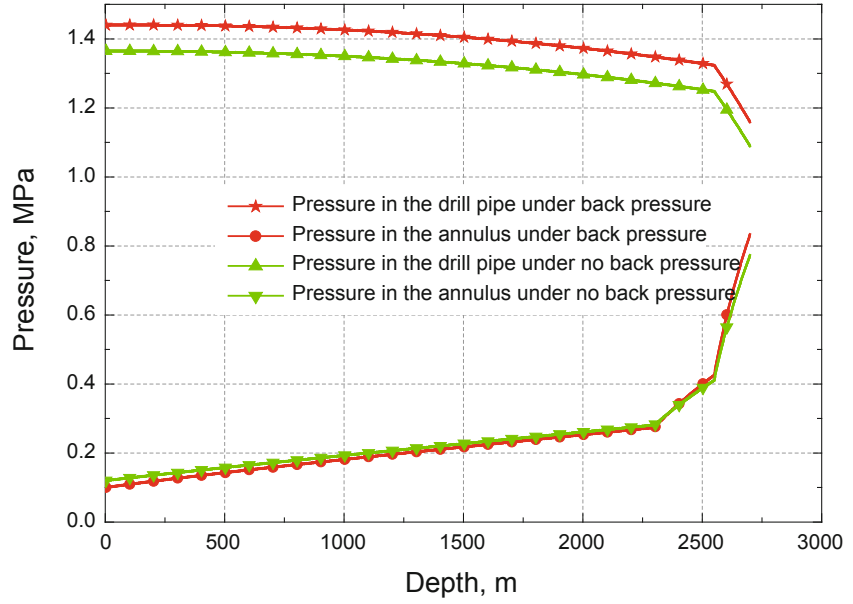

Fig. 5 The gas pressure distribution along the wellbore for recycling gas drilling

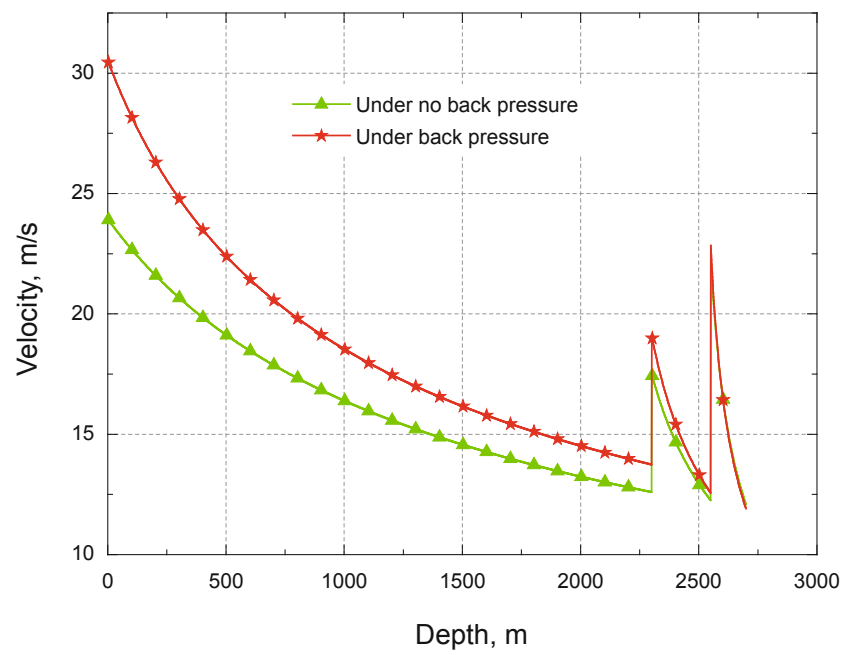

Fig. 6 The gas velocity distribution along the wellbore for recycling gas drilling

\subsection{The changes of kinetic energy at critical points during drilling}

An important aspect for successfully applying gas drilling technology lies in the selection of the critical point. The traditional selection criteria are the minimum kinetic energy method (Angel, 1957) and minimum velocity method (Johnson, 1995). This study adopted the minimum kinetic energy method. The critical point generally refers to a location in the annulus, at which the cross-section of the annulus changes. If, at the critical points, the kinetic energy does not meet the cuttings carrying capacity, a mud ring will be formed. The critical points in this case are the casing shoe and the top of the collar. The kinetic energy at the critical points must be greater than $214 \mathrm{~J} / \mathrm{m}^{3}$.

The kinetic energy equation is:

$$
E=\frac{1}{2} \rho_{\text {gas }} v^{2}
$$

where $E$ is the gas kinetic energy, $\mathrm{J} / \mathrm{m}^{3} ; v$ is the gas velocity, $\mathrm{m} / \mathrm{s}$.

Owing to the constant gas flow rate during conventional 
gas drilling, the gas velocity and density remain constant in the certain depth of wellbore. Therefore, the kinetic energy at the casing shoe is constant in gas drilling (Fig. 7). However, the depth of the collar top increases gradually during drilling, so the kinetic energy at this point decreases continuously. Further studies show that the selection of critical points is deeply affected by wellbore configuration. With the extension of the wellbore, the critical point changes from the casing shoe to the top of the collar.

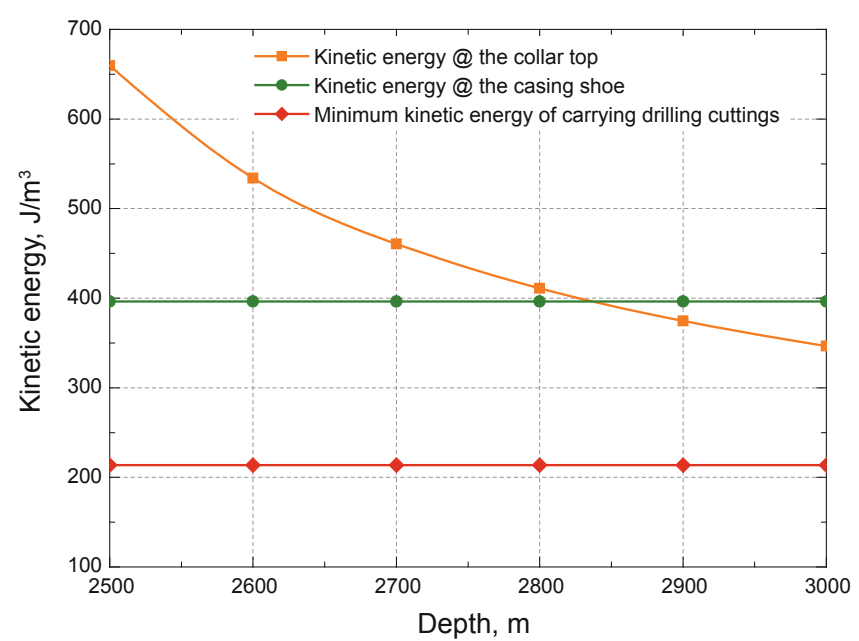

Fig. 7 Kinetic energy at the critical points changing with well depth for conventional gas drilling

Due to the decreasing gas flow rate and back pressure inhibiting gas expansion during recycling gas drilling, the kinetic energy at the casing shoe decreases linearly with well depth, and its value is consistently lower than the kinetic energy at the top of the collar (Fig. 8). Therefore, in this study, the casing shoe is the critical point. When drilling to the depth of $2,830 \mathrm{~m}$, the kinetic energy at the casing shoe cannot meet the capacity of carrying drilling cuttings and the gas supply must be increased. Deeper than this depth, the total mass of gas in the wellbore cannot maintain the normal transport of drilling cuttings without supplementation. This depth is called drilling limit of recycling gas drilling.

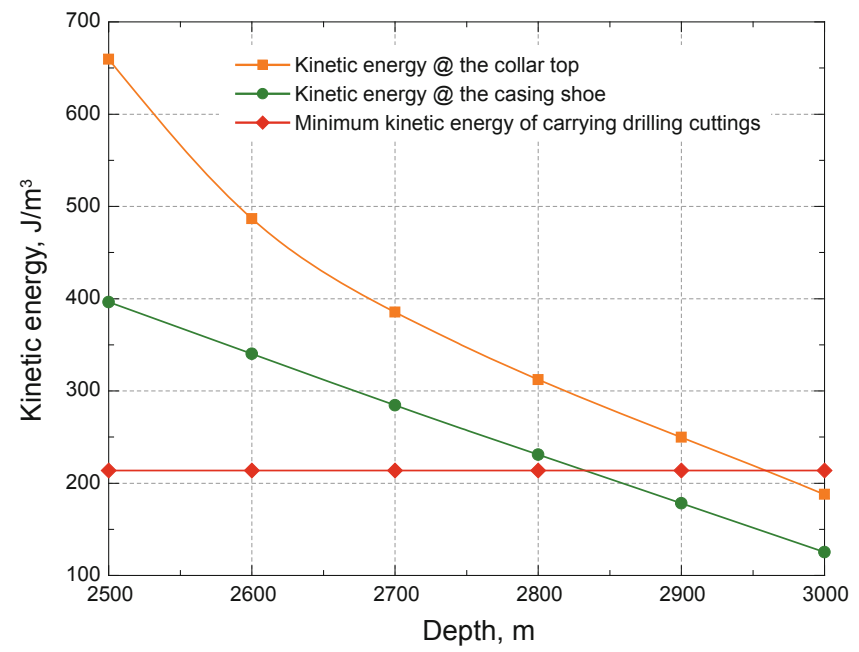

Fig. 8 Kinetic energy at the critical points changing with well depth for recycling gas drilling

\section{Gas supplement scheme}

Owing to the drilling limit, the total mass of gas in the wellbore at the ultimate depth is inadequate to carry cuttings. Therefore, a gas supplement operation must be conducted before drilling to this depth. This special operation will make the total mass of gas in the wellbore sufficient again to achieve normal drilling.

Likewise, controlling the total mass of gas in the wellbore is also very important. If the total mass of gas in the wellbore is excessive, the compressor will be choked and then stop working. However, if the total mass of gas in the wellbore is inadequate, compressor surge will occur. To solve this problem, the authors proposed two gas supplement schemes. One is the stage gas supplement scheme in which the gas supplement operation must be conducted before drilling to the ultimate depth. The other is the real-time gas supplement scheme in which the gas supplement operation should be conducted at all times in drilling in order to maintain the total mass of gas consistently sufficient.

\subsection{The stage gas supplement scheme}

To ensure safe drilling, the gas supplement operation is conducted each100 m. Compressor surge will occur if the supplied gas is excessive. Therefore, with the compressor under its normal working conditions, the supplement operation should be terminated when the circulating gas flow rate reaches the capacity of compressors. At this time, the whole operation will run into the next recycling gas drilling mode.

As shown in Fig. 9, the recycling gas drilling is operated at $2,500 \mathrm{~m}$. Since the total mass of gas in the wellbore remains fixed $(562 \mathrm{~kg})$, the gas flow rate decreases. Then, the gas supplement operation is conducted at a depth of 2,600 $\mathrm{m}$ and is terminated when the gas mass increases to $592 \mathrm{~kg}$. At this time, the gas flow rate recovers to $100 \mathrm{Nm}^{3} / \mathrm{min}$. The whole drilling process was repeated for each $100 \mathrm{~m}$ like this. The total mass of gas in the wellbore demonstrates a stepped increase (Fig. 10).

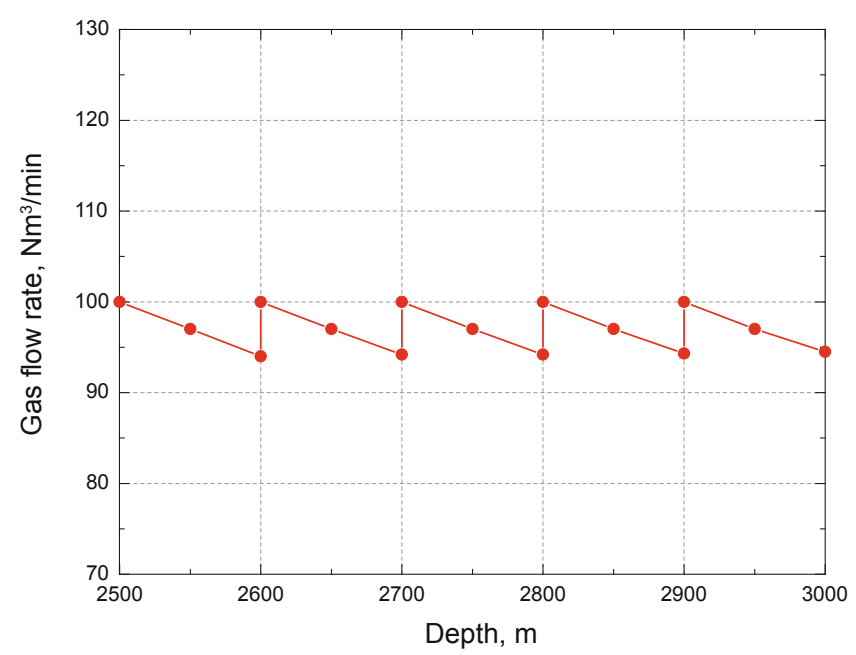

Fig. 9 The gas flow rate changing with well depth in the stage gas supplement scheme 


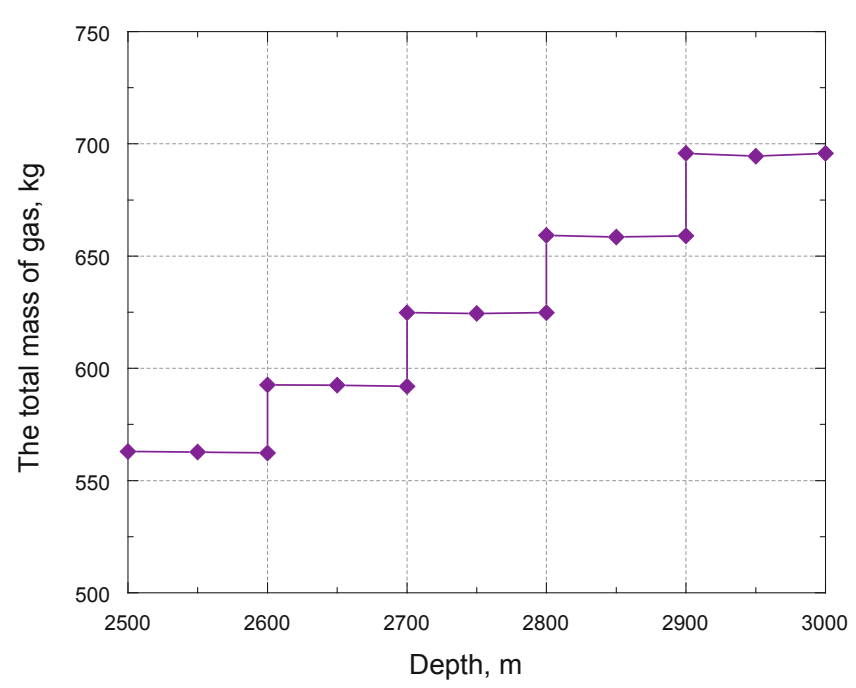

Fig. 10 The total mass of gas changing with well depth in the stage gas supplement scheme

\subsection{The real-time gas supplement scheme}

The starting point of this scheme is that the total mass of gas in the wellbore should be always adequate. This means that, the total mass of gas in the wellbore for recycling gas drilling should be the same as that for the conventional gas drilling under the same drilling conditions. This scheme not only can avoid drilling limit, but also brings the advantages of recycling gas drilling into full play. However, the real-time gas supplement rate must be controlled at all time in order to make the gas flow rate meet the requirement of capacity of the compressor. Its discrete formula is as follows:

$$
Q_{\text {sup }}\left(t_{j+1}\right)=\frac{M_{t_{j+1}}-M_{t_{j}}}{\rho_{0}\left(t_{j+1}-t_{j}\right)}
$$

The relationship between well depth and time is,

$$
H_{j+1}-H_{j}=\operatorname{rop} \times\left(t_{j+1}-t_{j}\right)
$$

where $t_{j}$ is the time; $M_{t}$ is the total mass of gas in the wellbore at time $t_{j}, \mathrm{~kg} ; \rho_{0}$ is the gas density under atmospheric pressure, $\mathrm{kg} / \mathrm{m}^{3} ; Q_{\text {sup }}\left(t_{j+1}\right)$ is the gas supplement rate at time $t_{j}$, $\mathrm{Nm}^{3} / \mathrm{min} ; H_{j+1}$ is the well depth at time $t_{j}, \mathrm{~m}$; rop is the rate of penetration, $\mathrm{m} / \mathrm{h}$.

The relationship between the gas supplement rate and well depth can be obtained by substituting Eq. (7) into Eq. (6). The recycling gas drilling is operated from $2,500 \mathrm{~m}$. At the same time, the gas supplement operation is conducted to ensure that the total mass of gas in the wellbore during recycling gas drilling is always consistent with that during conventional gas drilling. Due to the increasing bottom hole pressure and the compressibility of gas, the gas density of unit depth increment increase, which will further lead to the gas mass of unit depth increment increasing. Therefore, the gas supplement rate increases quasi-linearly with the depth extension as shown in Fig. 11. Simultaneously, the total mass of gas in the wellbore in recycling gas drilling conforms to that in conventional gas drilling (Fig. 12).

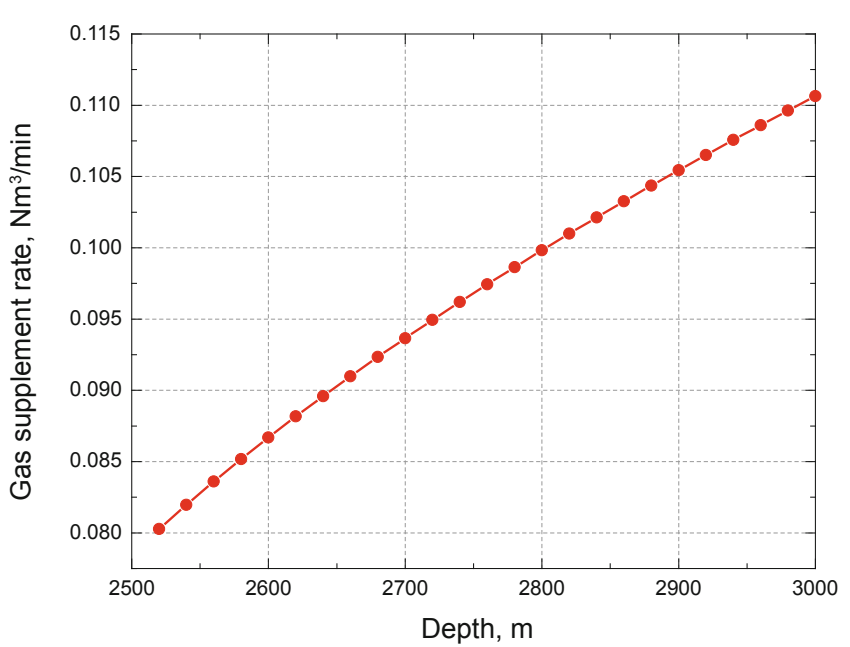

Fig. 11 The gas supplement rate versus well depth in the real-time gas supplement scheme

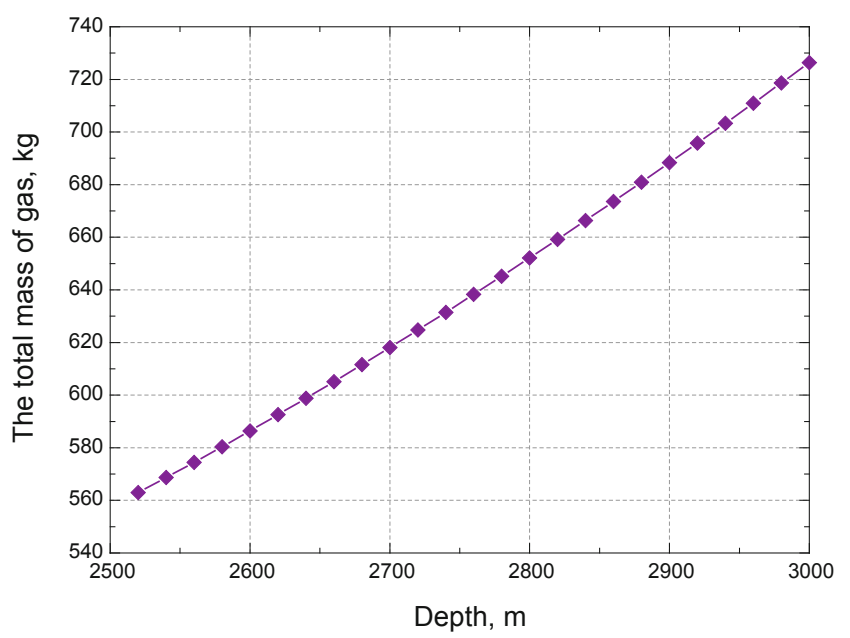

Fig. 12 The total mass of gas versus well depth in the real-time gas supplement scheme

\section{Conclusions}

1) The flow characteristics of recycling gas drilling were analyzed quantitatively. Because the total mass of gas in the wellbore is fixed, the gas flow rate decreases during drilling, which has an impact on the drilling cuttings transport.

2) Through analyzing the profiles of flow parameters, the impact of the back pressure on the gas flow rate was explained. The gas flow rate declines significantly with increases in the back pressure and the well depth. Moreover, the total decrease in the gas column pressure and the friction loss is greater than the back pressure, which makes the standpipe pressure during drilling at back pressure is lower than that when no back pressure is applied on the drilling fluid.

3) The selection of critical points for recycling gas drilling is different from that for conventional gas drilling. Moreover, the kinetic energy at the casing shoe is always lower than that at the top of the collar in recycling gas drilling but not in conventional gas drilling.

4) The concept of drilling limit is proposed in recycling 
gas drilling. At this depth, the total mass of gas cannot meet the capacity of carrying drilling cuttings, and additional gas must be added.

5) Two gas supplement schemes are proposed, namely the stage gas supplement scheme and the real-time gas supplement scheme. In actual operations, a combination of both schemes can be used to achieve optimal drilling performance.

\section{Acknowledgements}

The authors are grateful for the financial support from the National Natural Science Foundation of China (50974021) and Major Project of Chinese National Programs for Fundamental Research and Development (973 Program: 2010CB226704).

\section{References}

Allan P D. Nitrogen drilling system for gas drilling applications. Paper SPE 28320 presented at SPE Annual Technical Conference and Exhibition, September 25-28, 1994, New Orleans, Louisiana

Angel R R. Volume requirements for air and gas drilling. Pet. Trans. AIME. 1957. 210: 325-330

Chen G, Chen X, Liu D S, et al. The application of air and air/foam drilling technology in Tabnak Gas Field, Southern Iran. Paper SPE 101560 presented at the IADC/SPE Asia Pacific Drilling Technology Conference and Exhibition, November 13-15, 2006, Bangkok, Thailand

Coward H F and Jones G W. Limits of flammability of gases and vapors. U.S. Bureau of Mines Bulletin. 1952. 503

Cox R J, Li J and Lupick G S. Horizontal underbalanced drilling of gas wells with coiled tubing. SPE Drilling \& Completion. 1999. 14(1): 3-10

Fu S C, Sun G G, Li J, et al. The research on field test of gas drilling ground separation systems. Oil-Gas Field Surface Engineering. 2008. 27(12): 5-6 (in Chinese)

Fu S C, Sun G G and Ji Z L. Design and experiment study of ground separation equipment in gas drilling. Acta Petrolei Sinica. 2009. 30(2): 300-307 (in Chinese)

Gas Research Institute. Underbalanced Drilling Manual. GRI Reference No. GRI-97/0236. 1997. Chicago, IL

Guo B, Miska S Z and Lee R L. Volume requirements for directional air drilling. Paper SPE27510 presented at SPE/IADC Drilling Conference, February 15-18, 1994, Dallas, Texas

Hou X, Liu G, Hao L, et al. A new effective approach for successfully drilling into the naturally fractured reservoir (NFR): A field application study. Paper SPE 93725 presented at the SPE Middle East Oil and Gas Show and Conference, March 12-15, 2005, Kingdom of Bahrain

Johnson P W. Design techniques in air and gas drilling: Cleaning criteria and minimum flowing pressure gradients. Journal of Canada Petroleum Technology. 1995. 34(5): 18-26

Li J, Liu G H and Han L X. Study on the gas circulation drilling system. Drilling \& Production Technology. 2010. 3(3): 48-50 (in Chinese)

Li J, Liu G H and Wang X Z. Open loop field test of nitrogen circulation drilling system. Oil Drilling \& Production Technology. 2010. 32(3): 9-12 (in Chinese)

Liu G H, Tao Q and Li J. Gas volume control techniques for circular gas drilling. Oil Drilling \& Production Technology. 2009. 31(4): 32-35 (in Chinese)

Lunan B. Underbalanced drilling-surface control systems. Journal of Canada Petroleum Technology. 1995. 34(7): 29-35

Lyons W C, Guo B and Seidel F A. Air and Gas Drilling Manual. 2001. McGraw-Hill, New York

Lyons W C, Guo B, Graham R L, et al. Air and Gas Drilling Manual (3rd). 2008, Gulf Professional Publishing Company

Malloy K P, Medley G H and Stone C R. Air drilling in the presence of hydrocarbons: A time for pause. Paper SPE 108357 presented at the IADC/SPE Managed Pressure Drilling \& Underbalanced Operations, March 28-29, 2007, Galveston, Texas, U.S.A.

Nas S, Gala D and Cox P. Deep air drilling application to enhance rate of penetration in extremely hard, abrasive and high temperature environment. Paper SPE 132048 presented at the International Oil and Gas Conference and Exhibition in China, June 8-10, 2010, Beijing, China

Tao Q, Liu G H, Bi S Y, et al. Calculation of gas injection volume of gas cycling drilling and analysis on its influencial factors. Journal of Oil and Gas Technology. 2010. 33(1): 97-100 (in Chinese)

Teichrob R R. Low pressure reservoir drilled with air $/ \mathrm{N}_{2}$ in a closed system. Oil and Gas Journal. 1994. 92(12): 80-90

Wu Q W, Liu G H and Li J. The research on simulation method of gas circulation drilling in a similar way. Oil Drilling \& Production Technology. 2009. 31(5): 11-14 (in Chinese)

Zabetakis M G. Flammability characteristics of combustible gases and vapors. U.S. Bureau of Mines Bulletin. 1964. 627

Zhao Z X, Gao D L and Zheng D S. Mechanism of well deviation in air drilling and its control. Paper SPE 130201 presented at the International Oil and Gas Conference and Exhibition, June 8-10, 2010, Beijing, China

Zhu H J, Lin Y H, Meng Y F, et al. Influence of relevant parameters on hole cleaning and pipe string erosion in air drilling. Paper SPE 126515 presented at the SPE Oil and Gas India Conference \& Exhibition, January 20-22, 2010, Mumbai, India

(Edited Sun Yanhua) 